\title{
PELATIHAN PENGISIAN KONTEN WEBSITE KAMPOENG HERITAGE KAJOETANGAN
}

\author{
Irmalia Suryani Faradisa ${ }^{1}$, Febriana Santi W², Widhy Wahyani ${ }^{3}$ \\ Institut Teknologi Nasional Malang \\ e-mail : irmalia_suryani_faradisa@lecturer.itn.ac.id
}

\begin{abstract}
Abstrak - Kota Malang merupakan kota terbesar kedua setelah Surabaya di Jawa Timur, dan merupakan salah satu hasil perencanaan kota kolonial terbaik Hindia Belanda. Hal ini dapat dilihat dari banyaknya peninggalan arsitektur kolonial yang hingga saat ini masih berdiri megah dan tata lingkungan yang memiliki nilai historis. Pusat Kota Malang pada masa tahun 1914 terletak dikawasan Kajoetangan hingga alun alun kota Malang. Area Kajoetangan kota Malang terletakdi Jalan Basuki rahmat gang VI, Kelurahan Kauman Kecamatan Klojen. Sejak tanggal 22 April 2018 kampung Kajoetangan ditetapkan sebagai kawasan warisan budaya (heritage) oleh pemerintah kota Malang. Kampung Kajoetangan menawarkan wisata budaya bermuatan edukasi sejarah, dengan memperlihatkan arsitektur rumah peninggalan kolonial Belanda yang masih terjaga hingga saat ini. Ada sekitar 60 rumah yang teridentifikasi sebagai bangunan kolonial. Tidak hanya arsitektur bangunan, peralatan atau barang-barang kuno yang ada disana tapi juga kampung Kajoetangan masih menyimpan banyak sisa peradaban masa lalu semisal makam mbah Honggo Kusumo, kuburan tandak, pasar krempyeng, irigasi Belanda, saluran air,tangga seribu dan titik lain yang memiliki nilai sejarah tinggi di Kota Malang. Dengan segala kelebihannya sebagai kampung heritage menimbulkan dampak sosial terhadap perkembangan perekonomian di kampung tersebut. Sekarang kampung tersebut banyak dikunjungi oleh wisatawan lokal dan juga ada wisatawan mancanegara. Berdasarkan hal tersebut maka dibuat sebuah website untuk dapat mempublikasikan kampung Kajoetangan. Kegiatan abdimas bertujuan melatih dan mendampingi pemuda Kampung Heritage dalam pengisian konten website ini agar mereka dapat mengupdate website dengan keadaan yang terkini dari perkembangan kampung heritage. Manfaat yang diharapkan dari pelatihan ini adalah: Kampung Heritage dapat lebih terkenal dan diharapkan ekonomi masyarakat meningkat dengan banyaknya wisatawan yang berkunjung
\end{abstract}

Kata kunci: Kota Malang, Kampung Kajoetangan, Heritage, Pelatihan, Website

Abstract - Malang is the second largest city after Surabaya in East Java, and is one of
the best colonial city planning results of the Dutch East Indies. This can be seen from
the many relics of colonial architecture that still stand majestically and environmental
systems that have historical value. Malang City Center in 1914 was located in
kajoetangan area to Malang city square. Kajoetangan area of Malang city is located on
Jalan Basuki rahmat gang VI, Kauman Subdistrict Klojen. Since April 22, 2018
Kajoetangan village has been designated as a heritage area by the Malang city
government. Kampung Kajoetangan offers cultural tourism with historical education, by
showing the architecture of dutch colonial heritage houses that are still preserved to this
day. There are about 60 houses identified as colonial buildings. Not only the
architecture of buildings, equipment or antiquities that exist there but also kajoetangan
village still holds many remnants of past civilizations such as the tomb of Honggo
Kusumo mbah, tandak cemetery, krempyeng market, Dutch irrigation, waterways,
thousand stairs and other points that have high historical value in Malang. With all its 
advantages as a heritage village has a social impact on the economic development in the village. Now the village is visited by many local tourists and there are also foreign tourists. Based on this, a website was created to be able to publish kajoetangan village. Abdimas activities aim to train and assist kampung heritage youth in filling the content of this website so that they can update the website with the latest circumstances of the development of kampung heritage. The expected benefits of this training are: Kampung Heritage can be more famous and it is expected that the economy of the community will increase with the number of tourists visiting.

Keywords : Malang City, Kampung Kajoetangan, Heritage, Training, Website

\section{PENDAHULUAN}

Indonesia merupakan bangsa yang kaya raya. Baik kaya dalam suku, adat maupun bahasa. Sehingga Indonesia menjadi kaya akan makanan khas, sejarah dan berbagai macam bentuk aktivitas sosial budaya termasuk ritual dan perayaan keagamaan. Dari data statistik kebudayaan Indonesia 2019 yang diterbitkan Kementrian Pendidikan dan Kebudayaan (Kemendikbud). Warisan budaya tak benda Indonesia sangatlah banyak disebutkan mencapai 819 item. Terdiri dari 102 tradisi dan ekspresi lisan, 209 adat istiadat, ritus dan perayaan, 41 pengetahuan dan kebiasaan perilaku mengenai alam semesta, 271 seni pertunjukan serta 196 kemahiran dan kerajinan tradisional. Disamping kuliner dan budaya, bangunan adalah bukti lain yang dapat menceritakan masa lalu. Dari bangunan kita dapat memetik pelajaran dan hikmah dari cerita yang tersimpan. Bangunan-bangunan ini tersebar diseluruh wilayah Indonesia. Setiap tingkatan mulai desa hingga kota mempunyai bangunan bersejarah yang menjadi identitas dan ikon daerah tersebut. Masih dari data statistik kemendikbud tahun 2019 disebutkan bahwa jumlah arsitektur rumah berdasarkan jenis tiap provinsi ada sebanyak 175. Sedangkan jumlah cultural heritage (bangunan cagar budaya) yang tersebar dihampir semua provinsi di Indonesia mencapai 2.319. Kota Malang merupakan kota terbesar kedua setelah Surabaya Di JawaTimur, dan merupakan salah satu hasil perencanaan kota kolonial terbaik Hindia Belanda. Hal ini dapat dilihat dari banyaknya peninggalan arsitektur kolonial yang hingga saat ini masih berdiri megah (handinoto,2010) dan tata lingkungan yang memiliki nilai historis. Peninggalan arsitektural kolonial itu tersebar dalam bangunan yang dijadikan perkantoran, usaha, rumah tinggal, tempatibadah hingga bangunan sekolah.Peninggalan ini menjadi bukti perkembangan Kota Malang yang pesat dari sebuah kabupaten kecil menjadi kotamadya kedua terbesar di Jawa Timur yang terjadi antara tahun1914-1940 (Patricia,dkk 2014). Pusat Kota Malang pada masa tahun 1914 terletak dikawasan Kajoetangan hingga alun alun kota Malang. Area Kajoetangan kota Malang terletak di Jalan Basuki Rahmat gang VI, kaumanKlojen. Sejak tanggal 22 April 2018 kampung kayu tangan ditetapkan sebagai kawasan warisanbudaya (heritage) oleh pemerintah kota Malang (Radar Malang 2018). Setelah penetapan Kajoetangan sebagai salah satu area heritage, dimulai pula eksplorasi wilayah ini oleh para pecinta dan praktisi budaya di Malang Raya. Bahkan tahun 2019 untuk pertama kalinya digelar Oeklam oeklam Heritage Kajoetangan oleh masyarakat peduli warisan budaya yang tergabung dalam Malang raya Heritage (Malang Post, 2019). Kegiatan perdana tersebut berlangsung secara meriah dan dihadiri tidak saja oleh masyarakat sekitar tapi juga para wisatawan luar kota maupun mancanegara yang dengan antusias datang ke Kampung Kajoetangan. Kampung Kajoetangan menawarkan wisata budaya bermuatan edukasi sejarah, dengan memperlihatkan arsitektur rumah 
peninggalan colonial Belanda yang masih terjaga hingga saatini. Ada sekitar 60 rumah yang teridentifikasi sebagai bangunan kolonial. Tidak hanya arsitektur bangunan, peralatan atau barang-barang kuno yang ada disana tapi juga kampung Kajoetangan masih menyimpan banyak sisa peradaban masa lalu semisal makam mbah Honggo Kusumo (merupakan pembantu perjuangan pangeran Diponegoro), kuburan tandak, pasar krempyeng, irigasi Belanda, saluran air, tangga seribu dan titik lain yang memiliki nilai sejarah tinggi di Kota Malang. Dengan segala kelebihannya sebagai kampung heritage menimbulkan dampak sosial terhadap perkembangan perekonomian di kampung tersebut. Sekarang kampung tersebut banyak dikunjungi oleh wisatawan lokal dan wisatawan mancanegara .

Berdasarkan hal tersebut timbul ide bagaimana cara untuk dapat lebih mempublikasikan kawasan Kampung Heritage Kajoetangan ke dunia luar. Untuk itulah kami beserta tim berencana membuat sebuah website untuk dapat mempublikasikan kampung Kajoetangan. Setelah nantinya dibuat sebuah website tentu update dari sebuah website sangat dibutuhkan. Berdasarkan hasil survey lapangan kami melihat bahwa para pemuda karang taruna yang tergabung dalam kelompok sadar wisata (pokda) memiliki semangat yang tinggi untuk dapat mempublikasikan kampung mereka. Sampai saat ini sudah terbentuk 3 pokda. Dengan tingkat pendidikan rata rata adalah SMA dan sedikit yang PT sebenarnya kemampuan mereka untuk beradaptasi adalah tinggi. Untuk itulah kami membuat sebuah pelatihan pendampingan pengisian konten website terhadap para pemuda pokda. Dengan rata-rata usia muda dan produktif kami merasa pelatihan ini dapat dilaksanakan dan bermanfaat untuk perkembanganekonomi masyarakat kampung Heritage.

Tujuan yang ingin dicapai dalam kegiatan ini adalah mengadakan kegiatan pelatihan dan pendampingan dalam pengisian konten website ini adalah agar para pemuda kampong heritage dapat mengupdate website dengan keadaan yang terkini dari perkembangan kampung heritage.

\section{METODE}

Adapun metode pelaksanaan pada Program Pengabdian Kepada Masyarakat ini yaitu dengan metode transfer ilmu dari kami kepada pihak yang di suluh yaitu para pemuda karangtaruna kampung heritage.

Adapun metode pelaksanaan program adalah sebagai berikut :

\section{a. Survei dan Interview}

Survei telah dilakukan pada tanggal 9, 28 April 2020 Adapun tempat yang disurvei adalah sepanjang kampung heritage yang terdiri dari 3 RW yaitu RW 01 RW 02 dan RW 09. Sedangkan interview telah dilakukan pada tanggal 11 April 2020 dengan pak RW dan pada tanggal 20 dan 28 April interview dilakukan dengan ketua dan para pengurus karang taruna. Dan setelah melakukan koordinasi dengan pihak pihak tersebut menyatakan bersedia kerjasama dalam kegiatan Pengabdian Kepada Masyarakat yang dilaksanakan pada tahun anggaran 2020.

\section{b. Studi Literatur}

Mengadakan Studi literature tentang Website menggunakan bahasa pemrograman PHP dan database My SQL . Dan juga studi literature tentang kampong heritage di kota Malang.

\section{c. Persiapan}

Adapun tahapan persiapan kegiatan-kegiatan seperti : melakukan survey terhadap kampung heritage tersebut. Mempersiapkan penginstalan software bahasa pemrograman PHP dan database My SQL, mempersiapkan kuisioner yang akan 
diberikan diawal dan diakhir pertemuan pelatihan dan mempersiapkan pembuatan modul untuk pelatihan yang di berikan kepada para peserta.

\section{d. Waktu dan Tempat Pelaksanaan Kegiatan}

Kegiatan ini dilakukan selama 1 bulan dengan tempat pelaksanaan pengabdian yaitu di gedung serbaguna RW IX Kelurahan Kauman.

e. Tahap Pelaksanaan Kegiatan

Tahap pelaksanaan kegiatan adalah langkah pertama pembuatan modul.

Modul pelatihan dibagi menjadi dua bagian sesuai dengan pelaksaan kegiatan, meliputi :

1. Pengenalan website.

2. Pengisian Konten website.

Untuk Hasil dari pembuatan modul ini hasilnya dapat dilihat dilampiran berupa modul Pelatihan yang berjudul "modul Pelatihan Pengisian Konten Website bagi Karang Taruna di Lingkungan Kelurahan Kauman".

Sedangkan untuk tahap pelatihannya kegiatannya dibagi menjadi 2 tahap yaitu:

1. Tahap Pertama

Pada pelatihan tahap pertama, materi yang akan disampaikan meliputi pengisian kontenuntuk fitur-fitur sebagai berikut :

a. Beranda,

b. Event,

c. Kuliner.

Adapun media yang digunakan pada fitur-fitur ini adalah gambar, video, audio dan text.Digunakan fitur POST untuk mengisi konten pada fitur-fitur website tersebut.

2. Tahap Kedua

Pada pelatihan tahap selanjutnya, materi yang akan disampaikan meliputi pengisiankonten untuk fitur-fitur sebagai berikut :

\section{f. Evaluasi}

a. Tentang Kami,

b. Testimoni

Tahapan ini dilakukan untuk mengetahui tingkat keberhasilan kegiatan, sehingga dapat dilakukan penyempurnaan apabila ditemui kekurangan-kekurangannya.

Rancangan Evaluasi

Evaluasi ini bertujuan untuk mengetahui apakah terdapat peningkatan kemampuan dalam pengisian sesudah dilakukan pelatihan. Evaluasi dilakukan dengan dua kali sebelum dan sesudah pelatihan. Evaluasi dilakukan dalam pengisian kuisioner oleh peserta pelatihan. Kuisioner dimaksudkan untuk mengetahui pendapat dari peserta pelatihan mengenai kegiatan yang diadakan, sehingga dapat diketahui apakah tujuan dari kegiatan ini yaitu adanya peningkatan kemampuan dalam pengisian konten website sudah tercapai atau belum.

\section{HASIL DAN PEMBAHASAN}

Berdasarkan permasalahan yang telah dipaparkan maka diharapkan dapat memberikan jasa pelatihan pengisian konten website kepara pemuda karang taruna kampung heritage kojoetangan, sehingga website kampung heritage dapat terus update sesuaidengan keadaan terkini. Kegiatan pengabdian masyarakat yang di laksanakan di Kelurahan Kauman. Adapun susunan materi kegiatan dibagi menjadi 6 bagian meliputi : Registrasi, B. Login, C. Pengisian Konten Fitur Event, D. Pengisian Konten Fitur Kuliner, E. Pengisian Konten Fitur Akomodasi, F. Pengisian Konten Galery. 


\section{A. REGISTRASI}

Fitur registrasi digunakan untuk melakukan pendaftaran yang diperuntukkan untuk Admin pengelola Website. Pada tampilan beranda ini terdapat menu masuk untuk masuk kehalaman sign up.

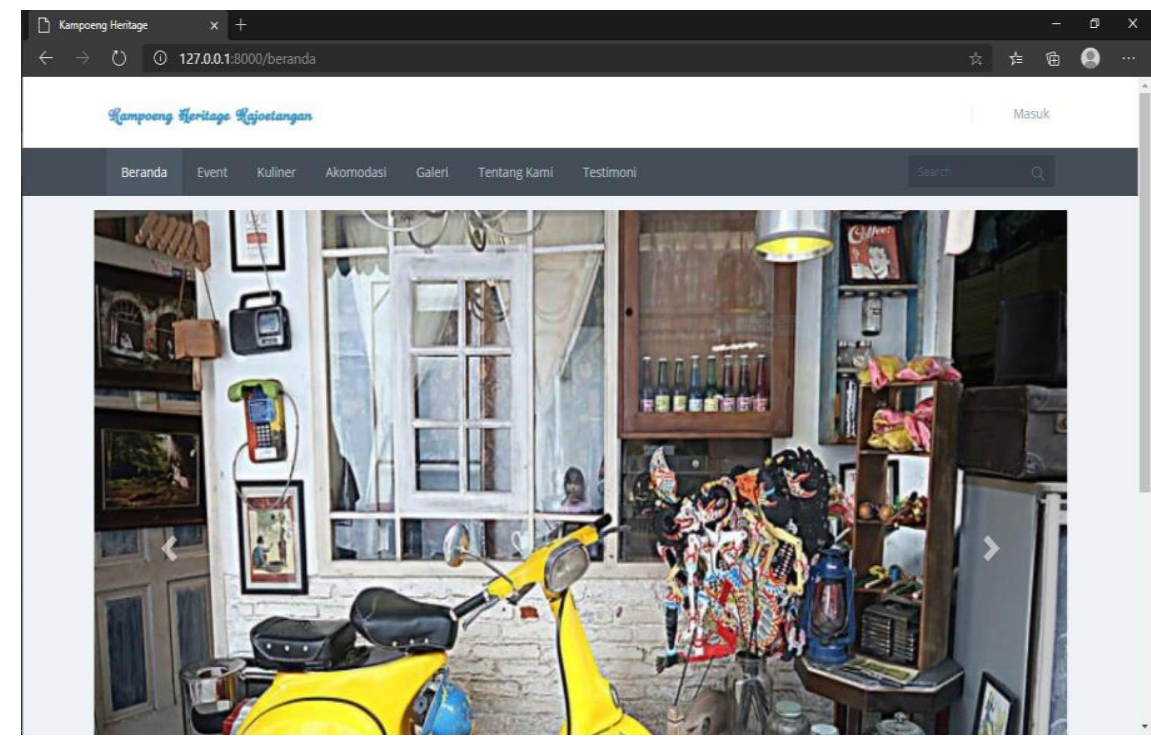

Gambar 1. Tampilan Menu Beranda

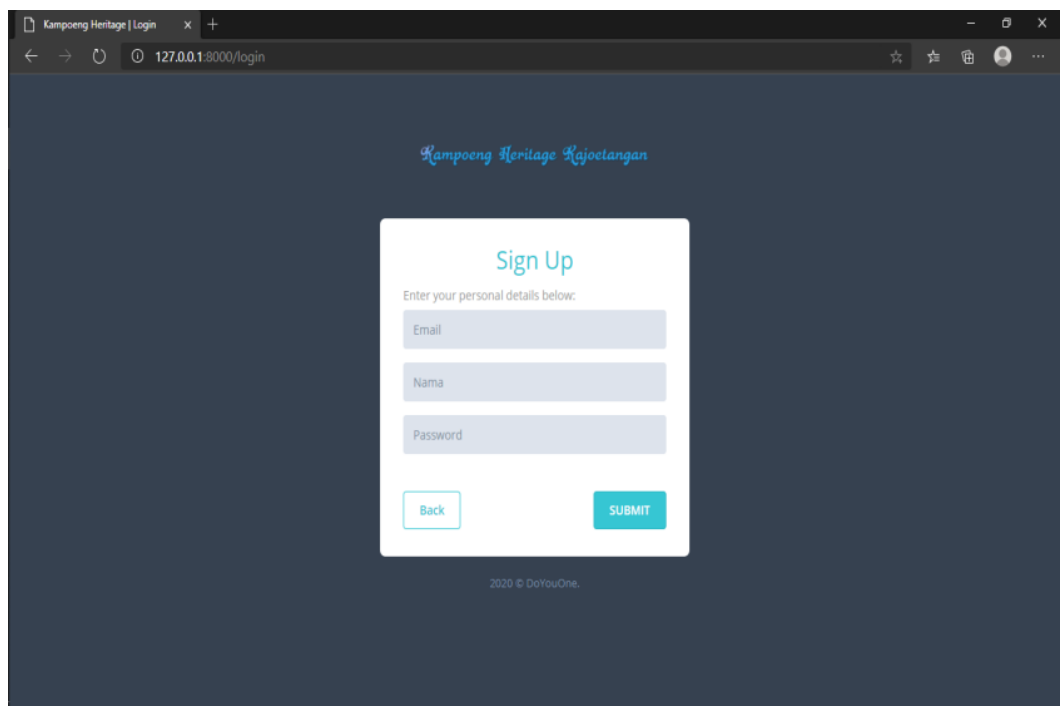

Gambar 2. Tampilan Menu Sign Up

\section{B. LOGIN}

Menu LOGIN merupakan menu yang digunakan untuk melakukan Login bagi Admin sehingga dapat mengakses website. 


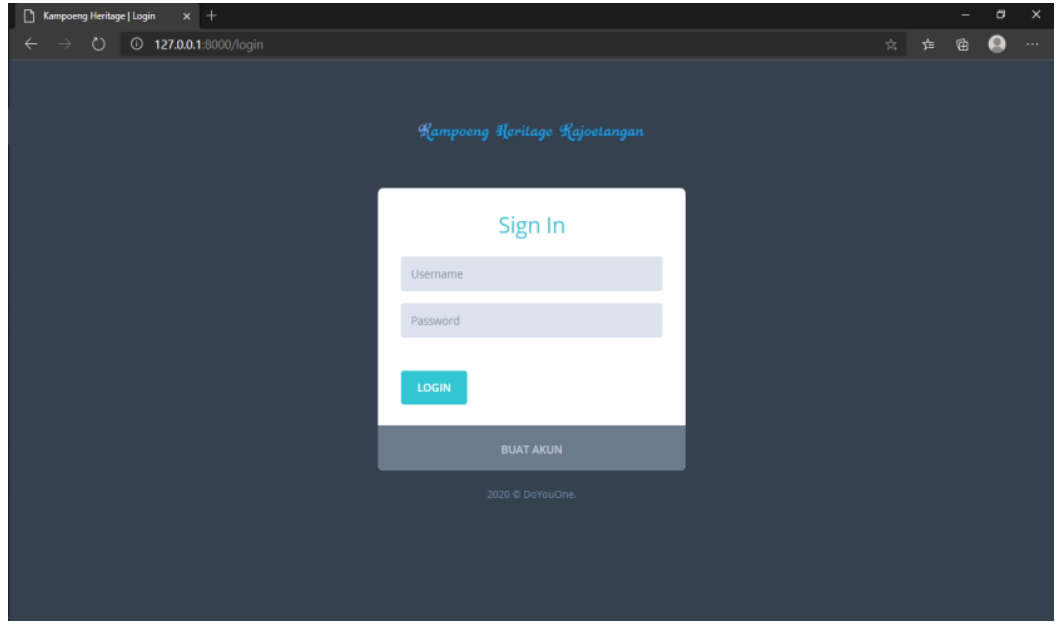

Gambar 3. Tampilan Menu LOGIN

\section{PENGISIAN KONTEN FITUR EVENT}

Fitur Event merupakan fitur yang digunakan untuk menampilkan acara-acara atau event-eventyang diadakan di lingkungan Kampoeng Heritage Kajoetangan.

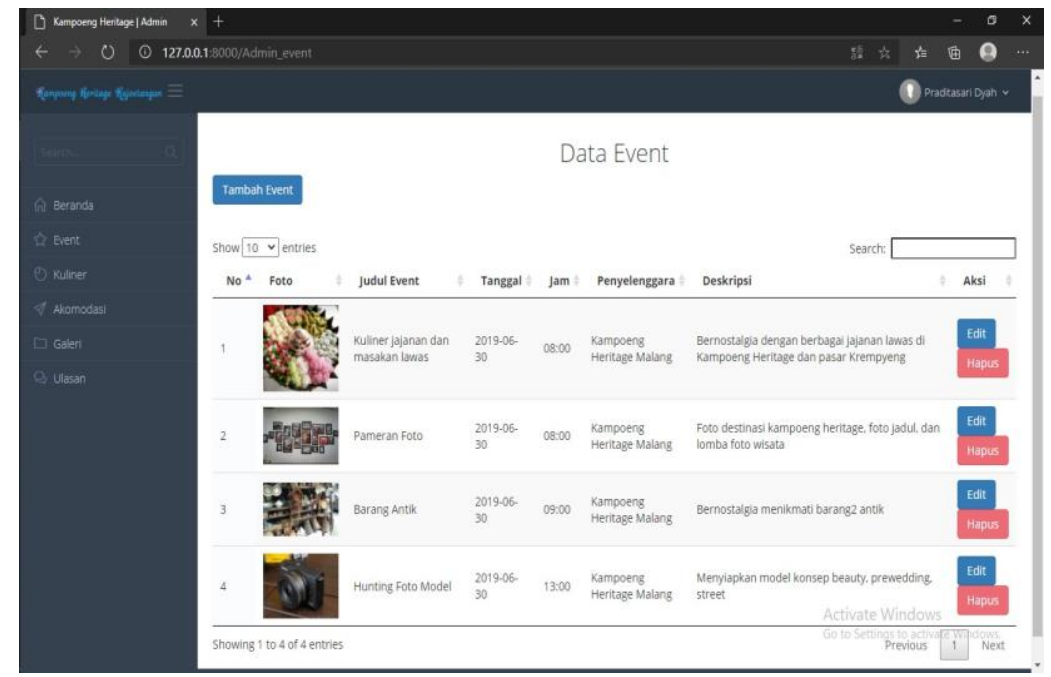

Gambar 4. Pengisian Konten Fiture Event

\section{PENGISIAN KONTEN FITUR KULINER}

Fitur Kuliner merupakan fitur yang digunakan untuk menampilkan kulinerkuliner yang dapatditemui di lingkungan sekitar Kampoeng Heritage Kajoetangan. 


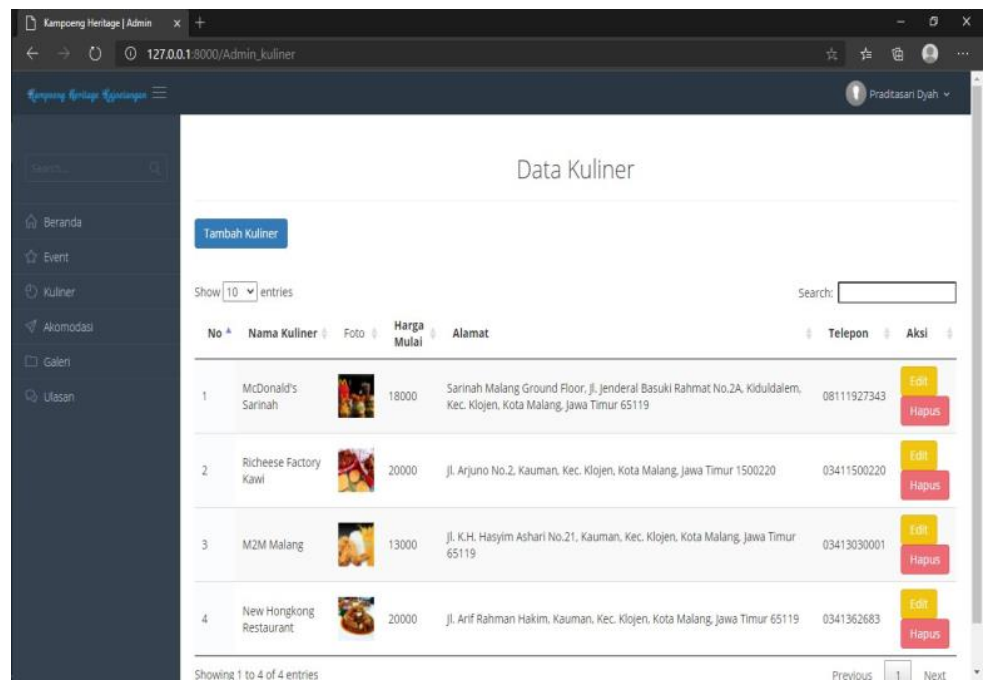

Gambar 5. Tampilan Data Kuliner

\section{E. AKOMODASI}

Fitur Akomodasi merupakan fitur yang digunakan untuk menampilkan akomodasi-akomodasi yang dapat ditemui di lingkungan sekitar Kampoeng Heritage Kajoetangan Tangan.

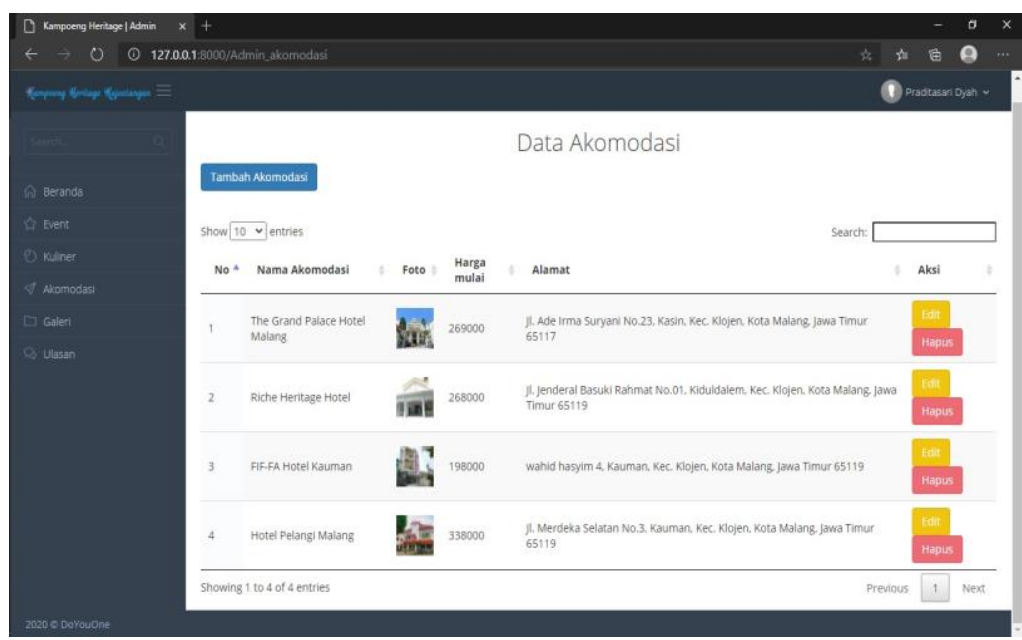

Gambar 6. Tampilan Halaman Data Akomodasi

\section{F. PENGISIAN KONTEN FITUR GALERY}

Fitur Gallery merupakan fitur yang digunakan untuk menampilkan Gallery fotofoto dari obyek-obyek wisata yang ada di Kampoeng Heritage Kajoetangan Tangan.

Jika memungkinkan, dapat disampaikan karya baru, alat/metode baru yang sesuai dengan perkembangan dan kebutuhan masyarakat agar memiliki nilai penting dan strategis berkenaan dengan penguatan sektor riil pada masyarakat. 


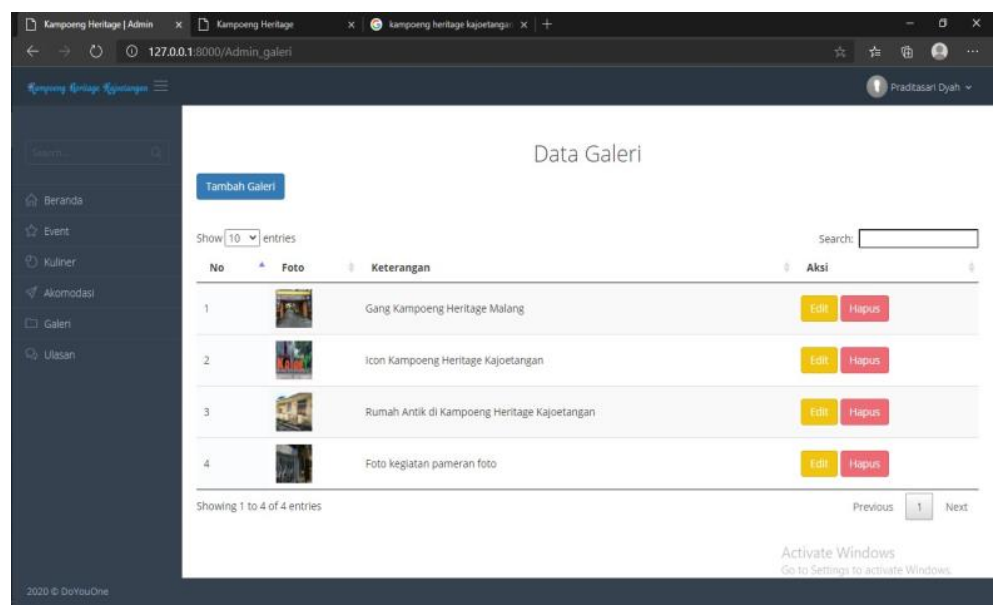

Gambar 7. Tampilan Halaman Data Gallery

\section{KESIMPULAN}

Kegiatan pengabdian pada masyarakat ini sesuai dengan kondisi terkini di Kota Malang dan sesuai dengan situasi masyarakat di Indonesia pada umumnya yang saat ini telah mengalami dampak terjadinya pandemi COVID-19. Ditambah lagi dengan segala kelebihannya, Kayoetangan sebagai kampung heritage menimbulkan dampak sosial terhadap perkembangan perekonomian di kampung tersebut. Apalagi kampung tersebut sering dikunjungi oleh wisatawan domestik maupun non domestik (mancanegara). Sehingga kegiatan pendampingan "Pelatihan Pengisian Konten Website bagi Karang Taruna di Lingkungan Kelurahan Kauman", sangat mendukung upaya dalam mempromosikan serta mempublikasikan kawasan Kampung Heritage Kayutangan ke seluruh penjuru dunia. Terlebih berdasarkan hasil survey lapangan kami melihat bahwa para pemuda karang taruna yang tergabung dalam kelompok sadar wisata (pokda) memiliki semangat yang tinggi untuk dapat mempublikasikan kampung mereka. Sampai saat ini sudah terbentuk 3 pokda. Dengan tingkat pendidikan rata rata adalah SMA dan sedikit yang PT sebenarnya kemampuan mereka untuk beradaptasi adalah tinggi. Untuk itulah kami membuat sebuah pelatihan pendampingan pengisian konten website terhadap para pemuda pokda. Dengan rata-rata usia muda dan produktif kami merasa pelatihan ini dapat dilaksanakan dan bermanfaat untuk perkembangan ekonomi masyarakat kampung Heritage.

\section{UCAPAN TERIMA KASIH}

Rasa terima kasih kami sampaikan kepada semua pihak yang telah berpartisipasi dan berkontribusi serta memberikan dukungan kebijakan dan pengarahan dalam penyusunan laporan kegiatan ini. Ucapan terima kasih juga kami sampaikan kepada Institut Teknologi Nasional Malang melalui Lembaga Penelitian dan Pengabdian Masyarakat, Kepada segenap pimpinan Kelurahan Kauman khususnya RW 10, 11 serta rekan-rekan Karang Taruna di Lingkungan Kelurahan Kauman, Malang. juga rekanrekan mahasiswa ITN Malang yang tergabung dalam tim kegiatan abdimas ini.

\section{DAFTAR PUSTAKA}

Penulisan pustaka: Nama penulis, tahun, judul penerbit, kota terbit dan hlaaman. sebagaimana pada contoh berikut :

Lalu Mulyadi, Budi Fathoni, Ester Prikasari,2019, Potensi Kampung Heritage sebagai

Destinasi Wisata Kota Malang, Deazha, Malang 
Handinoto, Paulus H 91996) Perkembangan Kota dan arsitektur colonial Belanda dimalang Andi Yogyakarta

Priyanto Hidayatullah dan Jauhari Khairul Kawistara, 2014, Pemrograman Web, Inforatika Bandung

Abdul KAdir, 2008, Dasar Pemrogrtaman web Dinamis menggunakan PHP, andi Offset, Yogyakarta

Handinoto. 2010. Arsitektur dan Kota-Kota di Jawa pada Massa Kolonial. Yogyakarta: Graha Ilmu.

Pusat Data dan Statistik Pendidikan dan Kebudayaan Kementerian Pendidikan dan Kebudayaan Kompleks Kemendikbud. 2019. Statistik Kebudayaan 2019. Pusat Data dan Statistik Pendidikan dan Kebudayaan Kementerian Pendidikan dan Kebudayaan Kompleks Kemendikbud, Gedung E Lantai 1.

Fathoni, Budi, Soewarni, Ida, Oktaviano, G., Ellza, Wedyantadji, Bambang. 2019. Pelestarian Bangunan Cagar Budaya Di Kawasan Kayutangan Kelurahan Kauman Kota Malang, Studi Kasus di Kampung Kayutangan, Kota Malang. IV:(55-62).

Anonim Februari Alun-alun Di Face Off Berkonsep hijau Modern . http://radarmalang.co.id/februari-alun-alun-di-face-off -berkonsep-hijau-modern1591.htm/pkl-padati-alunalun-malang. (Diakses tanggal 15 Januari 2020, jam 16.00 WIB).

Mbah Ukik. Pudarnya Keindahan Alun-alun Kota Malang. http://www.kompasiana.com/aremangadas/pudarnya- keindahan-alun-alun-kotamalang_552ff6c66ea834ff758b4586. (Diakses tanggal 15 Januari 2020, jam 15.00 WIB). 